\title{
Е.П. Кузнецова
}

\section{СОВЕРШЕНСТВОВАНИЕ СИСТЕМЫ УПРАВЛЕНИЯ ПРОИЗВОДСТВЕННОЙ КООПЕРАЦИЕЙ В ВОЛОГОДСКОЙ ОБЛАСТИ ${ }^{1}$}

В настоящее время для органов власти и управления и научного сообщества становятся актуальными вопросы развития региональной экономики, которые требуют эффективного решения. Одним из инструментов, способствующим решению проблем региональной экономики, является развитие производственной кооперации. В связи с чем автором предпринята попытка исследования данного процесса, а также разработки комплексного инструментария управления процессами производственной кооперации в регионе (на примере Вологодской области). В работе, на основе проведенного социологического опроса руководителей предприятий Вологодской области, отражено состояние кооперационного взаимодействия в регионе. Дана оценка уровня развития кооперации, выявлены проблемы, связанные с низким уровнем взаимодействия предприятий, а также недостающими методами эффективности от кооперации в регионе, в связи с чем автором изучена система управления производственной кооперацией в Вологодской области и предложены мероприятия по ее совершенствованию. Результаты, полученные в ходе исследования, вносят вклад в развитие и систематизацию теоретической базы рассматриваемой проблемы. Практическая значимость работы связана с возможностью использования полученных результатов исследования научными сотрудниками, аспирантами, магистрантами, бакалаврами, занимающимися проблемами развития производственной кооперации.

Ключевые слова: региональная экономика, производственная кооперация, система управления кооперацией в регионе, малый и средний бизнес.

DOI: $10.35634 / 2412-9593-2019-29-6-754-762$

\section{Введение}

Проблема развития региональной экономики считается одной из ключевых в экономической науке и представляет собой сложный процесс, который определяется многими социальноэкономическими факторами [1]. Одними из таких факторов являются слабое стимулирование хозяйственных субъектов к интенсификации производства и, соответственно, сложность производства высокотехнологичной продукции, которая связана с большими затратами от внедрения технологических инноваций, ее окупаемостью и востребованностью на рынке, неготовностью производственных фондов предприятий к осуществлению необходимой модернизации, отсутствием высококвалифицированных специалистов для реализации такого процесса и т.п. [2]. Данные факторы негативно влияют на развитие экономики субъектов РФ.

В настоящее время научным сообществом и органами власти и управления осуществляется поиск решения проблем, связанных с активизацией предпринимательства с целью создания инновационной продукции в регионах. Об этом свидетельствует факт разработки и реализации ряда национальных проектов. В паспорте нацпроекта «Малое и среднее предпринимательство и поддержка индивидуальной предпринимательской инициативы» предусмотрено обеспечение производственных субъектов МСП элементами инфраструктуры имущественной поддержки в виде промышленных парков, технопарков, направленных на создание качественно новых производств ${ }^{2}$. В национальном проекте «Наука» одной из стратегических задач, способствующих стимулированию бизнес-структур к созданию высокотехнологичной продукции, указана интеграция вузов и научных организаций и их кооперация с предприятиями, действующими в реальном секторе экономики ${ }^{3}$.

Данные документы регламентируют стратегические задачи, как на федеральном, так и на региональном уровне и определяют конкретные результаты, в том числе и по развитию взаимодействия бизнес-структур, которые необходимо достичь к 2024 г.

\footnotetext{
${ }^{1}$ Статья подготовлена в рамках государственного задания № 0168-2019-0006 «Управление процессами структурной трансформации экономики регионов на основе развития малого и среднего предпринимательства».

${ }^{2}$ Паспорт национального проекта «Малое и среднее предпринимательство и поддержка индивидуальной предпринимательской инициативы». URL:http:/government.ru/info/35563/.

${ }^{3}$ Паспорт национального проекта «Наука». URL: http://government.ru/info/35565/.
} 
На сегодняшний день одним из наиболее перспективных направлений развития взаимодействия бизнес-структур является производственная кооперация. Об этом свидетельствует ряд исследований, посвященных вопросам развития экономики региона [3-5].

Особенно актуально применение производственной кооперации в промышленно-развитых регионах, так как в них находится большой промышленный потенциал, включение в процессы кооперации которого способно наращивать предпринимательскую активность и создавать высокотехнологичную продукцию, тем самым обеспечивая развитие территории [6]. Одним из таких регионов является Вологодская область. На осуществление данного вида взаимодействия в регионе благоприятно влияют большие объемы промышленного производства (более 40 \% в структуре ВРП).

Однако опираясь на опыт ученых в изучении данной проблемы, который показал, что в настоящий момент нет единого комплексного подхода к обеспечению реализации процесса кооперации бизнес-структур, также слабо проработаны вопросы управления производственной коопераций в регионе. Поэтому фундаментальная научная задача исследования заключается в совершенствовании системы управления процессами производственной кооперации в Вологодской области.

\section{Результаты исследования}

Стоит подчеркнуть, что в рамках данной работы под производственной кооперацией автором понимаются долговременные договорные отношения между различными категориями бизнеса в сфере производства продукции, материально-технического обеспечения производственного процесса, научно-исследовательских разработок, осуществляемое с целью создания единого продукта за счёт использования производственных возможностей региона [7].

Для Вологодской области построение технологических цепей в рамках кооперации послужит стимулом для максимального использования имеющегося производственного и кадрового потенциала, являющегося в совокупности источником создания инновационных технологий, применение которых поспособствует переходу к более высокому технологическому укладу, росту конкурентных преимуществ региона и достижения целей его промышленной ${ }^{4}$ и социально-экономической политики.

В Стратегии социально-экономического развития Вологодской области на период до 2030 г. ${ }^{5}$ (далее по тексту Стратегия) одним из приоритетов социально-экономической политики региона является формирование пространства для развития научно-технологического потенциала и инновационной сферы, наукоемких и высокотехнологичных отраслей экономики.

В Стратегии прописано, что для реализации данного приоритета органам власти и управления необходимо решить следующие задачи:

- создать условия для развития внутрирегионального, межрегионального и международного сотрудничества субъектов деятельности в сфере промышленности, расположенных на территории области, в том числе путем создания стимулов к перерегистрации на территории Вологодской области организаций единых производственно-технологических цепочек;

- создать условия для активизации процессов внутриобластной кооперации и интеграции субъектов в сфере промышленности с образовательными, научными, финансовыми организациями, субъектами технологического предпринимательства, выступающими в качестве поставщиков и предоставляющими услуги высококачественного сервиса;

- развивать систему подготовки и повышения квалификации инженерно-технических кадров.

Стоит отметить, что социально-экономическое положение субъекта РФ в наибольшей степени зависит от состояния промышленного сектора. Однако, по мнению ряда специалистов в области проблем региональной экономики [8-10], в регионе отсутствует сбалансированное развитие сектора промышленности, которое возможно наладить за счет производственной кооперации. Поэтому было проанализировано развитие производственной кооперации в регионе с целью выявления слабых сто-

\footnotetext{
${ }^{4}$ По мнению А.И. Татаркина и О.А. Романовой современная промышленная политика в регионах должна строиться на системных отношениях между государственными и муниципальными органами власти, хозяйствующими субъектами, научными и общественными организациями для формирования структурносбалансированной, конкурентоспособной промышленности, интеллектуальное ядро которой представлено новейшим технологическим укладом.

${ }^{5}$ Стратегия социально-экономического развития Вологодской области на период до 2030 г. URL: http://docs.cntd.ru/ document/444743929.
} 
рон данного взаимодействия бизнес-структур и разработки рекомендаций для региональных органов власти и управления по расширению и усилению сотрудничества предпринимателей региона и увеличению эффективности их деятельности на территории Вологодской области.

Так, в 2018 г. ФГБУН ВолНЦ РАН был проведен социологический опрос руководителей промышленных предприятий региона. В опросе приняли участие 73 руководителя предприятий Вологодской области, задействованных в технологических цепочках в рамках производственной кооперации. Распределение респондентов соответствует генеральной совокупности количества промышленных предприятий региона, осуществляющих кооперационное взаимодействие. Ошибка выборки по опросу не превышает $7 \%$.

В опросе приняли участие представители бизнеса из 8 районов и 2 городских округов из 28 муниципальных образований области. Основное скопление опрошенных предпринимателей, осуществляющих процессы кооперации, расположено в г. Вологде $(47 \%)$, Череповце $(16 \%)$, Сокольском $(10 \%)$ и Шекснинском районе (8\%) (рис. 1$)$.

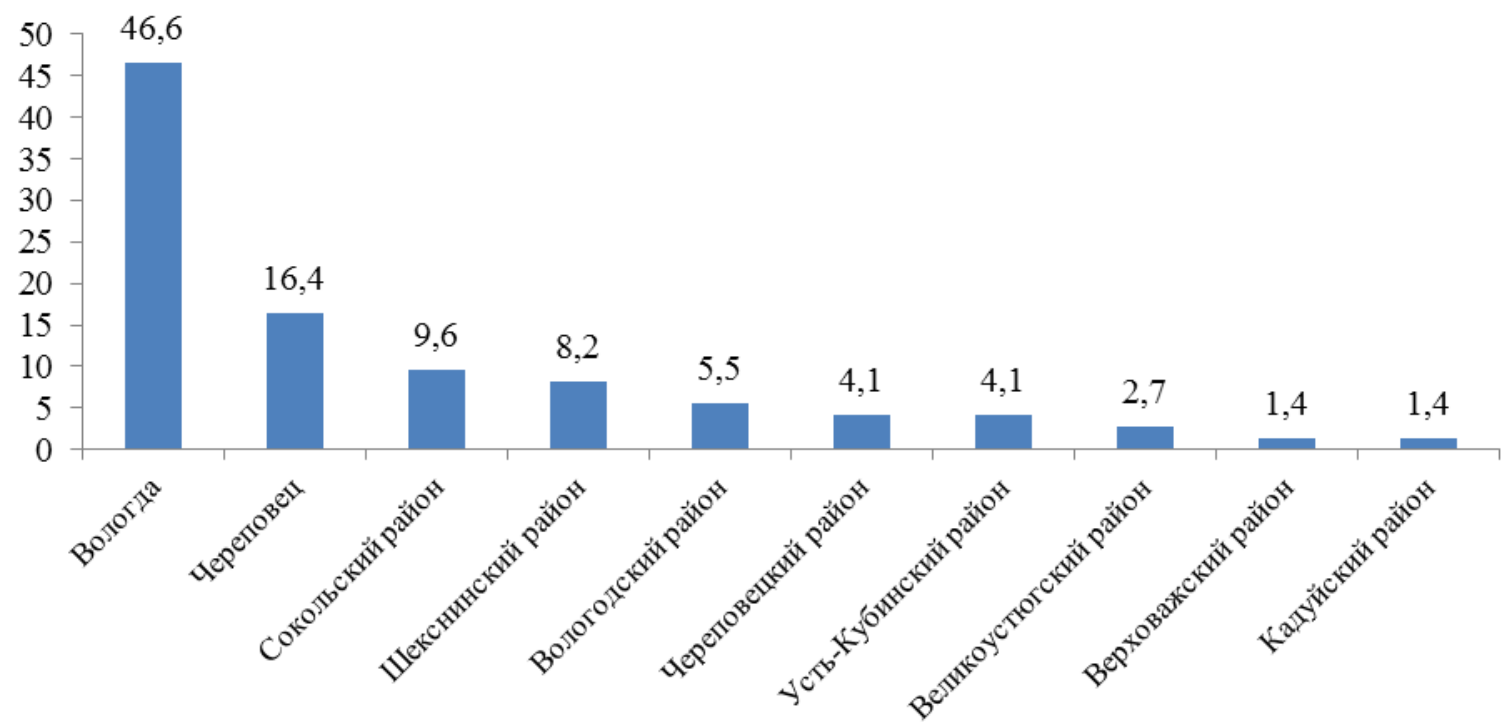

Рис. 1. Территориальная расположенность опрошенных предпринимателей, участвующих в проектах производственной кооперации в 2018 г., в \% от общего числа опрошенных

Источник: Составлено автором на основе социологического опроса руководителей промышленных предприятий Вологодской области, участвующих в производственной кооперации, проведенного ФГБУН ВолНЦ РАН в 2018 г.

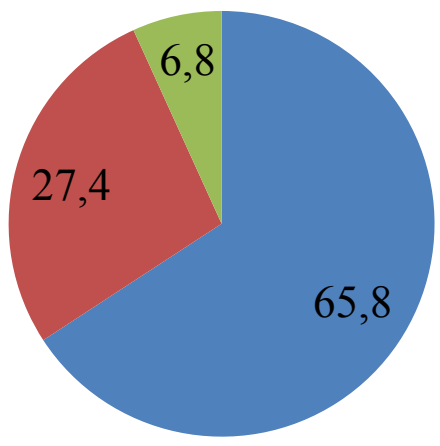

- Малое предприяте

- Среднее предприятие

- Крупное предприятия

Рис. 2. Структура бизнеса предприятий Вологодской области, участвующих в проектах производственной кооперации в 2018 г., \%

Источник: Составлено автором на основе социологического опроса руководителей промышленных предприятий Вологодской области, участвующих в производственной кооперации, проведенного ФГБУН ВолНЦ РАН в 2018 г. 
В кооперационном взаимодействии в большей степени заинтересованы представители малого бизнеса, их доля в общем количестве предприятий, участвующих в проектах производственной кооперации, составляет $68 \%$ (рис. 2). Доля участников среднего бизнеса региона от общего числа опрошенных составила $27 \%$. Самое низкое значение данного показателя по участию в производственной кооперации у крупных предприятий. Только 7 \% респондентов данной категории отметили, что взаимодействуют с бизнес-структурами в рамках кооперации.

На вопрос «В какой стадии технологической цепочки по созданию продукции в рамках кооперации задействовано Ваше предприятие?» 91 \% опрошенных ответили, что задействованы в стадии по производству конечного продукта (рис. 3). Порядка 19 \% респондентов обозначили себя на стадии дальнейшего улучшения продукции. 5 \% перерабатывают ресурсы в продукцию промежуточного назначения, и только около $2 \%$ предприятий занимаются добычей ресурсов.

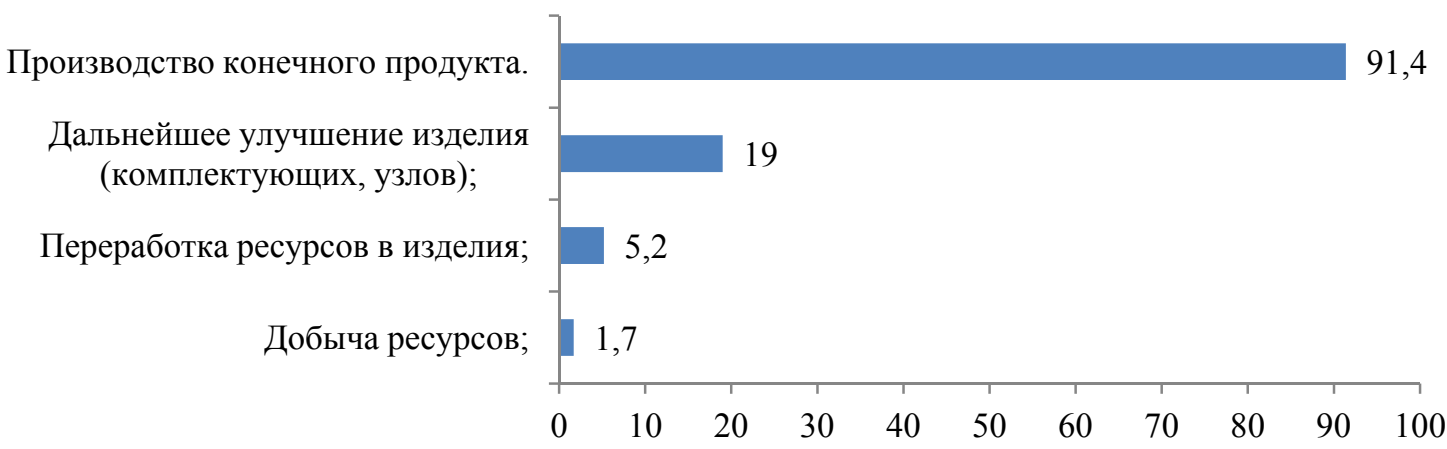

Рис. 3. Доля промышленных предприятий Вологодской области, задействованных в стадиях производства продукции в рамках производственной кооперации в 2018 г., в \% от общего числа опрошенных

Источник: Составлено автором на основе социологического опроса руководителей промышленных предприятий Вологодской области, участвующих в производственной кооперации, проведенного ФГБУН ВолНЦ РАН в 2018 г.

Промышленным предприятиям региона, встраивающимся в технологические цепочки в рамках производственной кооперации, удалось решить проблемы сбыта продукции (отметили 78 \% опрошенных), снизить издержки производства (62 \%) и получить дополнительную прибыль(60 \%) (рис. 4).

Получение прибыли

Проникновение на новые рынки и укрепление позиций на уже существующих

Снижение издержек производства

Оптимизация производственных запасов

Решение проблемы сбыта продукции

Доступ к ресурсам, которых у Вашего предприятия нет

Передача нерентабельной работы специализированным предприятиям с целью.

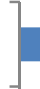

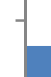

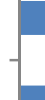

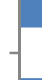
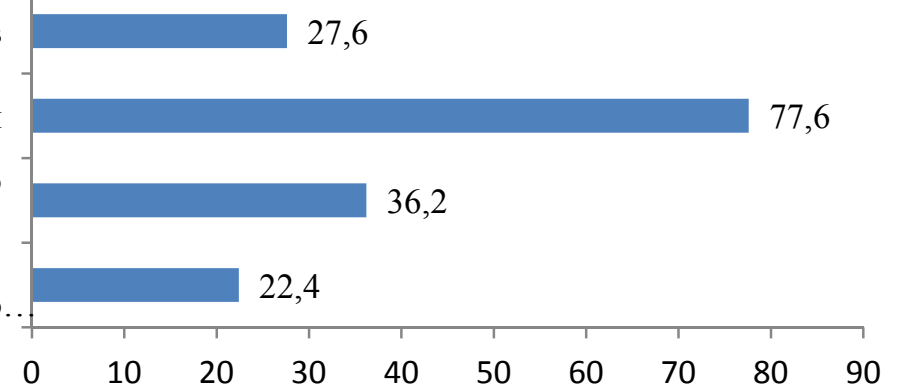

Рис. 4. Эффект от кооперации предпринимателей Вологодской области, \% Источник: Составлено автором на основе социологического опроса руководителей промышленных предприятий Вологодской области, участвующих в производственной кооперации, проведенного ФГБУН ВолНЦ РАН в 2018 г. 
Однако существует ряд проблем, препятствующих или не в полной мере позволяющих промышленным предприятиям региона встраиваться в технологические цепи в рамках кооперации. В первую очередь это отсутствие финансов и информации о потенциальных партнерах (отметили около $70 \%$ опрошенных) (рис. 5).

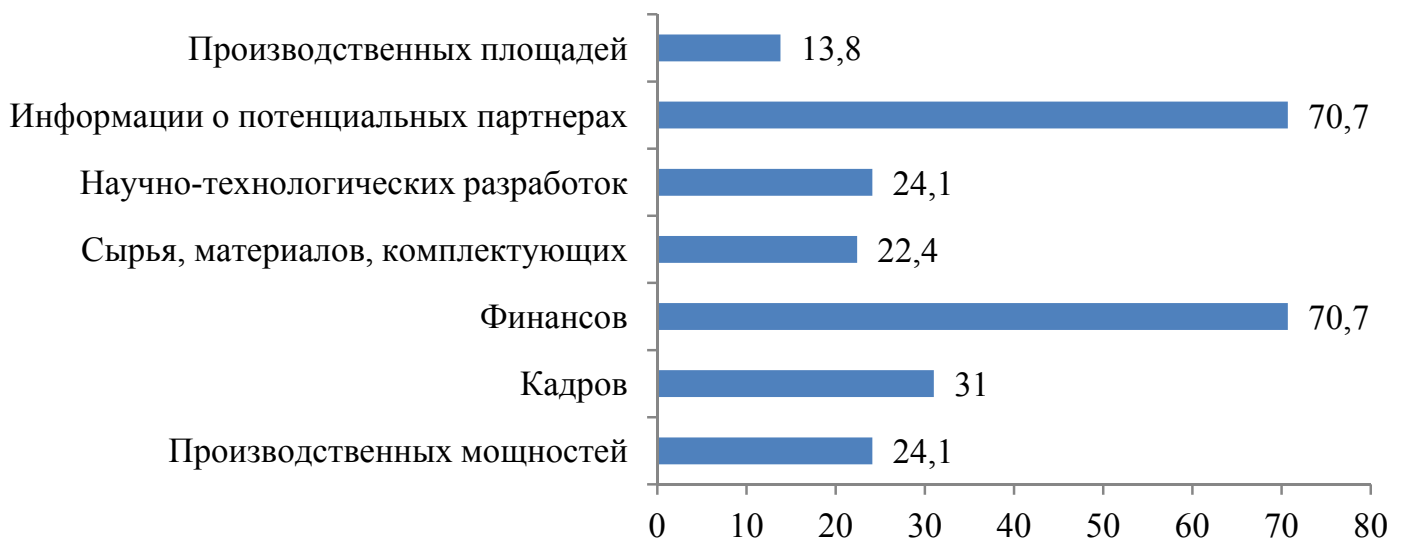

Рис. 5. Проблемы, с которыми сталкиваются промышленные предприятия Вологодской области, участвующие в производственной кооперации в 2018 г., в \% от общего числа опрошенных Источник: Составлено автором на основе социологического опроса руководителей промышленных предприятий Вологодской области, участвующих в производственной кооперации, проведенного ФГБУН ВолНЦ РАН в 2018 г.

Для решения выявленных проблем, препятствующих взаимовыгодному партнерству в рамках кооперации, предприниматели обращаются в банки, страховые компании, инвестиционные компании, различные фонды по оказанию финансовой поддержки, которая, как правило, выражается в получении денежных средств (отметили 16 \% опрошенных).

В большей степени устранению трудностей в кооперации предпринимателей содействуют региональные органы власти и управления (отметили около 31 \% опрошенных), как правило, это департамент экономического развития Вологодской области (рис. 6). Однако до 2018 г. содействие в построении кооперации со стороны представителей власти для создания и реализации продукции на территории субъекта РФ в основном носило формальный характер и оказывалось в виде информационно-организационных мероприятий. Так, на территории региона осуществлялись организации выставок, форумов и ярмарок, которые, как подчеркивают руководители предприятий, не оказывают существенной помощи (отметили $24 \%$ опрошенных).

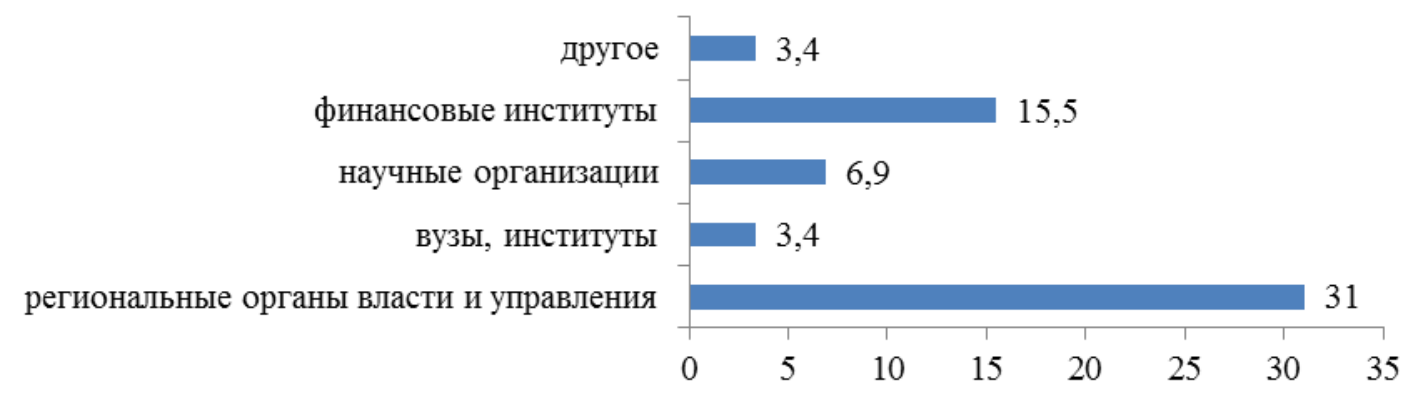

Рис. 6. Содействие промышленным предприятиям Вологодской области, участвующим в производственной кооперации в 2018 г., в \% от общего числа опрошенных Источник: Составлено автором на основе социологического опроса руководителей промышленных предприятий Вологодской области, участвующих в производственной кооперации, проведенного ФГБУН ВолНЦ РАН в 2018 г. 
На данный момент организационное и законодательное обеспечение управления производственной кооперацией в регионе также обеспечивается Департаментом экономического развития Вологодской области. Данный орган управления осуществляет мероприятия по стимулированию деятельности в сфере промышленности, создает условия для внутриобластной кооперации и интеграции субъектов в сфере промышленности с образовательными, научными, финансовыми организациями, субъектами технологического предпринимательства, выступающими в качестве поставщиков и предоставляющими услуги высококачественного сервиса, оказывает финансовую, имущественную, консультационную, информационную, маркетинговую и иную поддержку субъектам малого и среднего предпринимательства области.

При Департаменте созданы инфраструктурные организации, которые курируют организационные вопросы по развитию производственной кооперации в регионе посредством различных инструментов.

На региональном уровне организационная деятельность субъекта управления кооперацией промышленных предприятий осуществляется в лице АНО «Региональный центр поддержки предпринимательства» и НП Агентством городского развития путем экономических, правовых, организационных, информационных и образовательных инструментов.

Данные подведомства выполняют организационную работу по реализации мероприятий по «выращиванию» ${ }^{6}$ и «синергии роста» ${ }^{7}$, которая регламентируется приказом Департамента экономического развития Вологодской области от 13 июля 2018 г. № 0167/18-О «О реализации мероприятий по развитию бизнес-кооперации в Вологодской области» ${ }^{8}$, с помощью которой предприниматели могут взаимодействовать с бизнес-структурами в рамках осуществления госзакупок по законам 44, 223 ФЗ. Оказывают содействие в получении финансовой помощи. Проводят обучение предпринимателей ведению бизнеса.

Для участия в проекте «Синергия роста» руководитель предприятия осуществляет подачу заявки на имя председателя Совета по кооперации. После чего проводится квалификационная оценка потенциального участника, базирующаяся на данных об общей деятельности предприятия. Затем заключается соглашение о намерениях по вопросам развития бизнес-кооперации на территории области и реализации проекта. После чего заносится информация о предприятии в Реестр участников данного проекта.

Эффективность реализации проекта «Синергия роста» оценивается за счет таких показателей, как количество участников проекта, общий объем закупок товарно-материальных ценностей организаций крупного бизнеса у субъектов МСП региона, входящих в Единый реестр субъектов МСП, общая стоимость заключенных контрактов организациями крупного бизнеса области, другими крупными компаниями Российской Федерации, в том числе с иностранным участием, локализующими производство в Российской Федерации и субъектов МСП области, общая сумма предоставленной государственной финансовой поддержки организациям крупного, среднего и малого бизнеса области.

Реализация мероприятий по «выращиванию» субъекта МСП происходит в четыре этапа. На первом этапе осуществляется предварительный отбор субъектов МСП, включающий в себя подачу заявки на участие в мероприятиях, предварительную проверку сведений о предприятии, принятие региональной квалификационной комиссии решения о проведении квалификационной оценки.

Второй этап включает в себя проведение квалификационной оценки с целью разработки и реализации рекомендаций по «выращиванию».

На третьем этапе происходит «выращивание» субъекта МСП за счет выполнения необходимых для улучшения его деятельности, сформированных в индивидуальной карте развития предприятия.

\footnotetext{
${ }^{6}$ В регионе внедряются мероприятия по «выращиванию» субъектов МСП, направленные на увеличение количества активных, экономически стабильных субъектов МСП, выпускающих конкурентоспособные товары, работы, услуги, пользующиеся спросом на целевом отраслевом сегменте рынка.

${ }^{7}$ В Вологодской области реализуется проект «Синергия роста», основой которого является объединение крупного, среднего и малого бизнеса. Проект направлен на импортозамещение и обеспечение крупных предприятий продукцией малого и среднего бизнеса на основе договоров, заключенных на длительные сроки.

8 Приказ Департамента экономического развития Вологодской области от 13 июля 2018 г. № 0167/18-O «О peaлизации мероприятий по развитию бизнес-кооперации в Вологодской области». URL: http://docs.cntd.ru/ document $/ 550146380$.
} 
Заключительным этапом является вывод субъекта МСП на закупочные процедуры в соответствии с Федеральным законом от 18 июля 2011 г. № 223-Ф3 «О закупках товаров, работ, услуг отдельными видами юридических лиц».

Однако, на наш взгляд, в силу специфики требований для участия в закупках в рамках Ф3 «О закупках товаров, работ, услуг отдельными видами юридических лиц», применяемые инструменты государственного стимулирования к развитию бизнес-кооперации в регионе носят адресный характер, что не дает возможности расширению кооперации в регионе.

Важно отметить, что о реализуемых мерах государственной поддержки, направленной на содействие развитию производственной кооперации в Вологодской области, знает только половина опрошенных руководителей предприятий, из них участниками данных проектов являлись 3 предпринимателя (6\% от числа осведомленных о существующих мероприятиях по кооперационному взаимодействию в регионе). С одной стороны, это свидетельствует об отсутствии информированности предпринимателей о существующих мерах поддержки кооперационного взаимодействия в регионе. С другой - установлены высокие требования для участия в мероприятиях по содействию кооперации, регламентируемые приказом, которые приводят к субъективизму рассматриваемых заявок на оказание государственной поддержки.

Стоит также отметить, что в ранее проведенных исследованиях, посвященных проблемам кооперационного взаимодействия в регионе [11-13], была осуществлена оценка развития производственной кооперации в регионе [14]. Для этого автором разработан методический подход, определяющий данное взаимодействие по 5 уровням, описывающим состояние и причины неразвитости кооперации. Вологодская область вошла во второй уровень, характеризующийся невысокими партнерскими отношениями бизнес-структур, а также ограниченностью в возможностях кооперации. Ограничения в возможностях предпринимателей региона к кооперации связаны в первую очередь с низкой численностью предприятий, готовых сотрудничать, а также большими издержками на поиск информации о потенциальных партнерах и максимально выгодных условий в отношении цены на продукцию, качества необходимых комплектующих, деталей, узлов, заключения контракта. Данные причины, препятствующие взаимодействию бизнес-структур, негативно влияют и на экономику Вологодской области. Это выражается в увеличении значений показателя «смертности» малого и среднего предпринимательства (для примера в 2018 г. на территории области статус вновь созданных получили 3786 субъектов МСП, а приостановивших свою деятельность почти в полтора раза больше -4896$)^{10}$, снижении темпов роста промышленного производства, увеличении безработицы, неразвитости инновационной деятельности и т.п.

Отметим, что в существующей системе управления производственной кооперацией в регионе имеется ряд недостающих методов эффективности реализации кооперационного взаимодействия, которые бы активизировали предпринимательство, ускорили создание высокотехнологичной продукции и усилили конкурентоспособность территории. Для этого необходимо качественное оказание государственной поддержки, направленной на развитие производственной кооперации в регионе. На наш взгляд, одним из таких инструментов послужит разработка и реализация программы развития производственной кооперации в Вологодской области, целью которой будет являться повышение в отраслях промышленности региона кооперационных связей, направленных на создание высокотехнологичной продукции, способной обеспечить качественное увеличение ВРП, удовлетворение потребностей территории региона в основных видах конкурентоспособной продукции, значительное увеличение денежных средств в областной бюджет, существенное повышение качества жизни населения.

В качестве стратегических задач для решения выявленных проблем автором предлагается разработка программных мероприятий, целью которых будет являться повышение в отраслях промышленности региона кооперационных связей, направленных на создание высокотехнологичной продукции, способной обеспечить качественное увеличение ВРП, удовлетворение потребностей территории региона в основных видах конкурентоспособной продукции, значительное увеличение денежных средств в областной бюджет, существенное повышение качества жизни населения.

\footnotetext{
${ }^{9}$ Федеральным закон от 18 июля 2011 г. № 223-Ф3 «О закупках товаров, работ, услуг отдельными видами юридических лиц». URL: http://docs.cntd.ru/document/902289896.

${ }^{10}$ В Вологодской области снижается число малых и средних предприятий, а многие представители бизнеса смотрят в будущее со скептицизмом. Областная общеполитическая газета «Премьер». URL: https://premier.region35.ru/ article/delo-za-malym.
} 
Система программных мероприятий должна состоять из пяти блоков.

Первый блок должен содержать мероприятия по выявлению проблем развития производственной кооперации в регионе и приоритетных направлений ее развития.

Второй блок должен содержать организационную поддержку развития региональной производственной кооперации. В этом блоке особое значение отводится мероприятиям по организации эффективного взаимодействия предприятий.

Третий блок должен включать мероприятия по разработке образовательных программ, методических рекомендаций для управленческих кадров с целью построения эффективного взаимодействия в регионе.

Четвертый должен включать в себя мероприятия по информационной поддержке региональной производственной кооперации.

Пятый блок должен быть направлен на разработку нормативно-правовых актов по развитию производственной кооперации в регионе.

Кроме того, необходимо формирование единой информационной базы для поиска потенциальных партнеров и установления делового партнерства, которая будет являться одним из важнейших инструментов поддержки предпринимателей и активизации развития производственной кооперации в Вологодской области. Цель такой базы будет заключаться в формировании благоприятных условий осуществления производственной деятельности в регионе за счет кооперации предприятий.

Таким образом, управление производственной кооперацией в регионе должно осуществляться комплексно и представлять собой целостную систему, направленную на содействие активизации и усиления производственной кооперации в Вологодской области. Для ее работы необходима разработка организационно-экономического механизма управления кооперацией предпринимателей региона, который будет представлен на следующем этапе исследования.

Результаты, полученные в ходе исследования, вносят вклад в развитие и систематизацию теоретических и методических аспектов рассматриваемой проблемы и должны быть полезными для научных сотрудников, аспирантов и студентов, занимающихся вопросами региональной экономики.

\section{СПИСОК ЛИТЕРАТУРЫ}

1. Гранберг А.Г. Основы региональной экономики. М.: ГУ-ВШЭ, 2006. 495 с.

2. Porter M.E. (ed.) Competition in Global Industries. Boston: Harvard Business School Press, 1986.

3. Ускова Т.В., Лукин Е.В. Межрегиональное взаимодействие как фактор роста экономики: препринт. Вологда: ИСЭРТ РАН, 2013. 76 с.

4. Романова О.А., Макарова И.В. Кооперация как условие конкурентного развития региона // Региональная конкуренция. 2009. № 3 (15). С. 67-80.

5. Блягоз А.В. Совершенствование форм и механизмов взаимодействия экономических субъектов в системе региональной экономики (по материалам Краснодарского края): автореф. дис. ... канд. экон. наук: 08.00.05. Майкоп, 2010. 29 с.

6. Скопина И.В., Скопин А.О. Комплексное развитие региональной производственной кооперации и кластерных проектов // Региональная экономика и управление. 2007. № 1 (9). URL: https://eee-region.ru/article/901/ (дата обращения 09.09.2018).

7. Кузнецова Е.П. Основные подходы к понятию кооперационных связей малого и крупного бизнеса // Вопр. территориального развития. 2017. № 4 (39). URL: http://vtr.isert-ran.ru/article/2359.

8. Проблемы развития промышленного сектора экономики старопромышленных регионов России / Т.В. Ускова [и др.] // Экономические и социальные перемены: факты, тенденции, прогноз. 2017. Т. 10, № 4. С. 62-77. DOI: $10.15838 /$ esc.2017.4.52.3.

9. Лукин Е.В., Мельников А.Е. Модернизация промышленного сектора экономики старопромышленных регионов СЗФО // Проблемы развития территории. 2017. № 5 (91). C. 32-43. URL: http://pdt.vscc.ac.ru/article/2345.

10. Гулин К.А., Мазилов Е.А., Ермолов А.П. Импортозамещение как инструмент активизации социальноэкономического развития территорий // Проблемы развития территорий. 2015. № 3 (77). С. 7-25.

11. Кремин А. Е. Оценка влияния деятельности малого бизнеса на уровень социально-экономического развития региона // Современные научные исследования и инновации. 2015. № 11. URL: http://web.snauka.ru/issues/ 2015/11/59180 (дата обращения 23.10.2018).

12. Вертакова Ю.В., Петрищева И.В. Алгоритм стратегической оценки взаимодействия малых и крупных бизнес-структур // Всерос. журн. научных публикаций. 2012. № 2. С. 30-34.

13. Костусенко А.И. Процесс измерения эффективности взаимодействия предпринимательских структур // Проблемы современной экономики. 2009. № 2 (30). С. 18-25. 
14. Кузнецова Е.П. К вопросу оценки развития производственной кооперации в регионе // Проблемы развития территории. 2019. № 5 (103).

15. Уланова О.Н. Оптимизация взаимодействия крупного и малого предпринимательства в инновационной среде: автореф. дис. ... канд. экон. наук: 08.00.05. М., 2013. 24 с.

Поступила в редакцию 27.10.2019

Кузнецова Екатерина Петровна, аспирант, младший научный сотрудник отдела проблем научно-технологического развития и экономики знаний лаборатории инновационной экономики ФГБУН ВолНЦ РАН

160014, Россия, г. Вологда, ул. Горького, д. 56 а

E-mail: 333.maarel.333@mail.ru

\section{E.P. Kuznetsova \\ IMPROVEMENT OF THE MANAGEMENT SYSTEM OF PRODUCTION COOPERATION IN VOLOGDA OBLAST}

DOI: $10.35634 / 2412-9593-2019-29-6-754-762$

Currently, the issues of development of the regional economy, which require an effective solution, are becoming relevant for government and management bodies and the scientific community. One of the tools that contribute to solving the problems of the regional economy is the development of industrial cooperation. In this connection, the author made an attempt to study this process, as well as to develop comprehensive tools for managing the processes of industrial cooperation in the region (for example, Vologda Oblast). The work, on the basis of a sociological survey of the heads of enterprises of Vologda Oblast, reflects the state of cooperation in the region. An assessment of the level of development of cooperation is given, problems associated with a low level of interaction between enterprises, as well as lacking methods of efficiency from cooperation in the region are identified, in connection with which the author studied the management system of production cooperation in Vologda Oblast and proposed measures to improve it. The results obtained during the study contribute to the development and systematization of the theoretical basis of the problem under consideration. The practical significance of the work is related to the possibility of using the results of the research by researchers, graduate students, undergraduates, bachelors dealing with the problems of development of industrial cooperation.

Keywords: regional economy, industrial cooperation, cooperation management system in the region, small and mediumsized businesses.

Kuznetsova E.P., postgraduate student, Junior Researcher at Department of problems of scientific and technological development and knowledge economy

Laboratory of Innovation Economics

Gor'kogo st., 56a, Vologda, Russia, 160014

E-mail: 333.maarel.333@mail.ru 